\title{
Analysis and Improvement of the Steering Characteristics of an ATV.
}

\author{
1. Dr. S. Neelakrishnan, ${ }^{2}$. Kowshik T, ${ }^{3}$. Krishnakumar G, \\ 4 . Bharathi Mohan M P \\ 1, 2, 3, 4 (Department of Automobile Engineering, PSG College Of Technology, Coimbatore-04
}

\begin{abstract}
The main objective is to analyze the steering characteristics of an ATV (All Terrain vehicles) in order to improve the maneuverability of the vehicle. It is found that in our last year's BAJA buggy the vehicle oversteerd more than we expected, when inputs are given in the steering wheel while cornering at sharp turns which tends to move the vehicle out of the track. We focus to design an effective steering system with a reduced steering ratio
\end{abstract} of 3:1. This helps the driver to maneuver the vehicle with ease.

\section{INTRODUCTION}

A Steering gear box helps to steer the front wheels of the vehicles which includes commercial vehicles, passenger vehicles, an ATV (All Terrain vehicles), etc. There are various types of steering gear boxes among which rack and pinion gear is considered to be more precise as it consists of fewer parts easier to control, respond to the inputs given and less backlash. The rack is housed in a casing.

The casing is supported on the frame near its ends. The ends of the rack are connected to the track rod with the help of a ball joint or Heim joint. The pinion shaft is carried in the bearings housed in a casing. The pinion meshes with the rack. Its main objective is to convert the rotational motion of the steering wheel to the linear motion of the rack. While the driver turns the steering wheel the column rotates the pinion gear which in turn meshes with the rack, then the linear motion is transferred to the drive wheels via the track rod.

The steering ratio is the main criteria for designing the steering system. It is nothing but the number of degrees of rotation of the steering wheel to the number of degrees of rotation of road wheels. The steering ratio varies based on the applications, which in changes the diameter of the steering wheel accordingly. Generally, the steering ratio for passenger cars is $14: 1$. In case of heavy vehicles it is $20: 1$. The number of degrees of rotation of steering wheel increases with increase in steering ratio. Rack and pinion steering is quickly becoming the most common type of steering on cars, small trucks and SUVs.
II. DESIGNED PARTS OF STEERING SYSTEM:

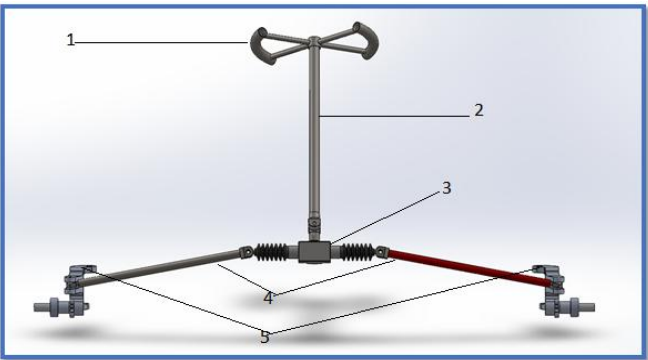

Fig 1: Parts of steering system.

$\begin{array}{ll}\text { 1. Steering wheel 2. Steering column } & \end{array}$

3. Steering gearbox 4. Tie rod

5. Steering Upright

Design Methodology for Steering System:

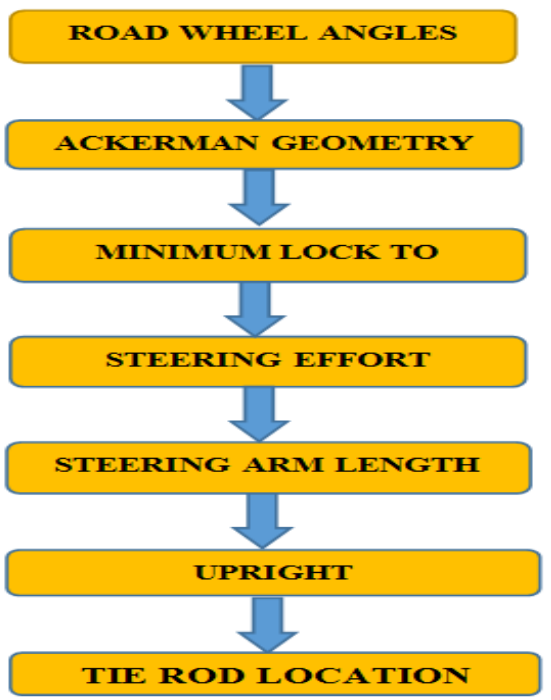

Fig 2: Design methodology flow chart. 
The main objective of this project is to design a steering system based on the flow chart shown in fig 1 . The design process starts with the road wheel angles, Ackerman geometry, the minimum lock to lock, steering effort, steering arm length, Upright and Tie rod location.

Ackermann steering plays an important in a steering system as it enables the vehicle to steer the vehicle without slippage of the tire. Secondly, the minimum lock to lock of the steering wheel is kept by optimizing the steering ratio of $3: 1$ in order to have better maneuverability for a BAJA buggy. Then followed by steering effort and wheel alignment parameters are considered. Wheel alignment parameters include camber, caster, steering axis inclination, Toe-in and Toe-out. The angles of all the wheel alignment parameters are specified based on the requirement of BAJA buggy. Hence, on the whole the dynamic behavior and stability of the vehicle is improved by studying the steering characteristics.

\section{Design Process, Analysis And Simulation:}

The complete CAD modelling is done in solid works software, including Rack and pinion gear box, steering upright, Tie rod, steering column and steering wheel. It is important to carry out analysis for all the custom made parts. Ansys software is used for analysis to check the component strength, fatigue life which includes components factor of safety, equivalent stress and total deformation to ensure safety design standards.

After carrying out analysis, simulation is carried out with the help of Lotus shark software by generating the coordinates from the CAD assembly. The dynamic behavior of wheel alignment parameters, bump steer and Ackerman percentage is checked with respect to steer travel. The graphs were generated after simulation.

\section{Design Caculations:}

1.1.1 Rack and pinion gear Box:

\begin{tabular}{|l|c|c|}
\hline \multicolumn{1}{|c|}{ Parameter } & Rack & Pinion \\
\hline No. of Teeth & 22 & 23 \\
\hline Length & $356 \mathrm{~mm}$ & $52 \mathrm{~mm}$ \\
\hline Diameter & $20 \mathrm{~mm}$ & $34 \mathrm{~mm}$ \\
\hline Pressure Angle & $20^{\circ}$ & $20^{\circ}$ \\
\hline Travel & $4.25^{\prime}$ & $270 \mathrm{deg}$ \\
\hline
\end{tabular}

Table 1: Rack and Pinion Specifications

\section{Steering Components Cad Modelling: \\ 2.1 Rack:}

Cad modelling is done for rack with 4.25 " rack travel. It consists of 22 teeth. Heim joints are fixed at both the ends of the rack to connect the tie rod. The total length of rack travel is 14 ".

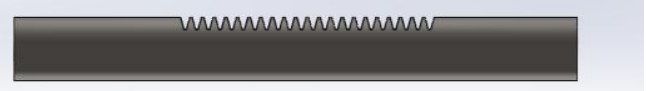

\subsection{Pinion:}

Fig 3: CAD modelling of rack.

Pinion gear is designed with 23 teeth with a travel of 270 degree from lock to lock.

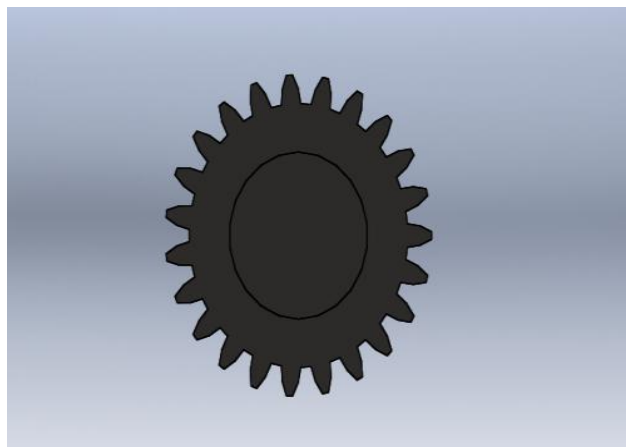

Fig 4: CAD Modelling of pinion.

\subsection{Rack and pinion gearbox casing:}

Casing is designed to cover the rack and pinion assembly. Nylon bushings are provided at both the ends of casing for rack sliding. Ball Bearing is placed at the center to enhance the rotatory motion of the pinion. Backlash adjustment is provided at the bottom side of the casing to avoid the free play.

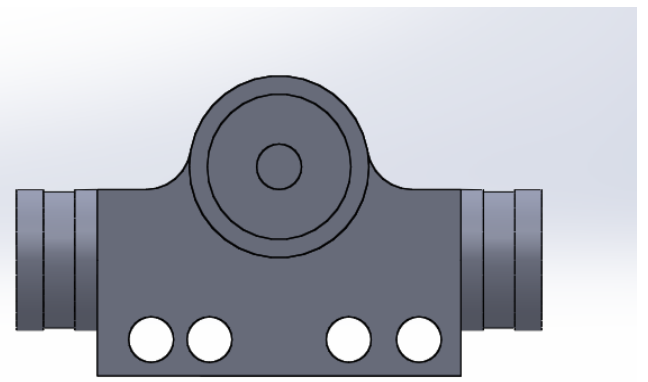

Fig 5: CAD modelling of rack and pinion Gear box casing.

The casing also incorporates the mounting holes of $8 \mathrm{~mm}$ diameter of 4 holes for rigid mounting. The casing is supposed to made-up of the Aluminium materials for weight reduction. 


\subsection{Rack and pinion assembly:}

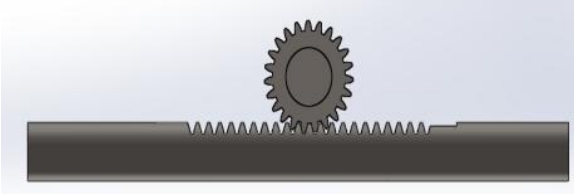

Fig 6: Rack and pinion assembly.

2.5 Final assembly of Steering gear box:

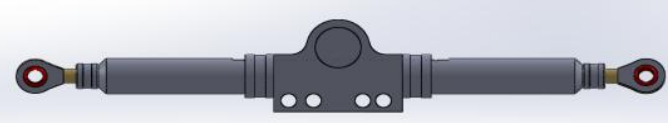

Fig 7: Steering gear box assembly.

\section{CALCULATIONS}

\subsection{Specifications:}

\begin{tabular}{|l|l|}
\hline Wheel base & $1561 \mathrm{~mm}$ \\
\hline Front track & $1350 \mathrm{~mm}$ \\
\hline Rear track & $1244 \mathrm{~mm}$ \\
\hline Turning circle radius(g) & $1900 \mathrm{~mm}$ \\
\hline $\begin{array}{l}\text { Lock to lock angle(Steering } \\
\text { wheel) }\end{array}$ & 360 degrees \\
\hline Diameter of the steering wheel & $300 \mathrm{~mm}$ \\
\hline Rack travel & $107.95 \mathrm{~mm}$ \\
\hline Tie rod length & $320 \mathrm{~mm}$ \\
\hline Steering effort & $65 \mathrm{~N}$ \\
\hline Steering ratio & $3: 1$ \\
\hline Caster angle & $10 \mathrm{deg}$ \\
\hline Kingpin inclination & $10 \mathrm{deg}$ \\
\hline
\end{tabular}

Table 2: Specifications

\subsubsection{Steering Effort:}

\section{VERTICAL MOMENT:}

$\mathrm{Mv}=-(\mathrm{Fzl}+\mathrm{Fzr}) \mathrm{d} \sin \gamma \sin \sigma+(\mathrm{Fzl}-\mathrm{Fzr}) \mathrm{d} \sin \mathrm{V} \cos \sigma$ Dynamic load $=$ FAW $+\mathrm{L} . \mathrm{T}$

$\left(w^{*} a * h / g * L\right)$

$$
=(210 * 0.45 * 9.81)
$$

$$
\begin{aligned}
& =(927)+(283) \\
& =1410 \mathrm{~N}
\end{aligned}
$$$$
\mathrm{Fzr}=710 \mathrm{~N}, \mathrm{Fzl}=700 \mathrm{~N}
$$

LEFT TURN:

$\mathrm{Mv}=-$ Fzl d $\sin \gamma \sin \sigma \mathrm{i}-$ Fzr d $\sin \gamma \sin \sigma o+$ Fzl d $\sin \gamma \cos \sigma i$ - Fzr d $\sin \gamma \cos 60$

$$
=\quad-700 * 45 * \sin (10) * \sin (45)-
$$

$710 * 45 * \sin (10) * \sin (36)$

$+700 * 45 * \sin (10) * \cos (4)-$

$710 * 45 * \sin (10) * \cos (36)$

$=-7749.5 \mathrm{Nmm}$

RIGHT TURN:

$\mathrm{Mv}=-$ Fzl d $\sin \gamma \sin \sigma o-$ Fzr d $\sin \gamma \sin \sigma i+$ Fzl d sin $\gamma \cos \sigma o-$ Fzr d $\sin \gamma \cos \sigma i$
$=-700 * 45 * \sin (10) * \sin (36)-710 * 45 * \sin (10)$ $* \sin (45)+700 * 45 * \sin (10) * \cos (36)-710 * 45 * \sin$ (10) $* \cos (45)$

$=-6646 \mathrm{Nmm}$

\section{LATERL MOMENT:}

$$
\begin{aligned}
\mathrm{ML}= & (\mathrm{Fyl}+\mathrm{Fyr}) * \mathrm{r} * \tan \mathrm{V} \\
\mathrm{Fyl} & =\mu \mathrm{Fzl}=0.45 * 700=315 \mathrm{~N} \\
\mathrm{Fyr} & =\mu \mathrm{Fzr}=0.45 * 710=319 \mathrm{~N} \\
& =(315+319) * 285 * \tan (10) \\
& =31860 \mathrm{Nmm}
\end{aligned}
$$

TRACTIVE MOMENT

$$
\begin{aligned}
\mathrm{Mt} & =(\mathrm{Fxl}-\mathrm{Fxr}) * \mathrm{~d} \\
& =(710-700) * 45=450 \mathrm{Nmm}
\end{aligned}
$$

\section{EQUIVALENT TORQUE:}

$$
\text { Equivalent torque }=28963 \mathrm{Nmm}
$$

\section{STEERING EFFORT:}

Steeringeffort=EquivalentTorque/(steeringwheel radius $* \mathrm{~S}$. $\mathrm{R}$ )

$$
\begin{aligned}
& =28963 /(150 * 3) \\
= & 65 \mathrm{~N} .
\end{aligned}
$$

\subsubsection{PINION DESIGN AND CALCULATION:}

Pinion Torque $=$ Equivalent Torque/Steering ratio

$$
\begin{aligned}
& =28963 / 3 \\
& =9654 \mathrm{Nmm}
\end{aligned}
$$

$\mathrm{Ft}=$ Pinion Torque/(PCD/2)

$$
\begin{aligned}
& =9654 / 23 \\
& =419 \mathrm{~N} .
\end{aligned}
$$

Bending Stress $\sigma \mathrm{b}=\mathrm{Ft} * \mathrm{q} . \mathrm{k} * \mathrm{q} . \mathrm{e} / \mathrm{b} * \mathrm{~m}$

$$
\begin{aligned}
& =419 * 1 * 2.7 / 3.5 * 2 \\
& =162 \mathrm{~N} / \mathrm{mm}^{2} .
\end{aligned}
$$

Design bending stress (Tension):

$$
\begin{aligned}
& {\left[\boldsymbol{\sigma}_{\boldsymbol{b}}\right]=\frac{\boldsymbol{k}_{\boldsymbol{b l} \boldsymbol{l}}}{\boldsymbol{n} \cdot \boldsymbol{k}_{\boldsymbol{\sigma}} \boldsymbol{\sigma}_{-1}}} \\
& \mathrm{x}=(\mathrm{t} / \mathrm{m}-\mathrm{pi} / 2) /(2 * \tan \alpha) \\
& \text { Where, } \mathrm{t}=\text { thickness of teeth. } \\
& \mathrm{m}=\text { module } \text {. } \\
& \alpha=\text { pressure angle. } \\
& x=(3.5 / 2-3.14 / 2) /(2 * \tan (20)) \\
& =0.25 \\
& \boldsymbol{K}_{\boldsymbol{\sigma}}=1.3 \\
& \sigma_{-1}=0.35 \sigma_{u}+1200 \\
& =3211.005+1200 \\
& =4411.005 \mathrm{kgf} / \mathrm{cm}^{2} \\
& {\left[\sigma_{b}\right]=\frac{1 * 4411.005}{2 * 1.3}=1696 \mathrm{kgf} / \mathrm{cm}^{2}} \\
& =170 \mathrm{~N} / \mathrm{mm}^{2}
\end{aligned}
$$

So, the material is safe.

Pressure angle $\alpha=20 \mathrm{deg}$

Module $\mathrm{m}=2$

Number of teeth $\mathrm{Z} 1=23$ 


$$
\begin{aligned}
\text { Pitch circle dia }(\mathrm{d} 1) & =\mathrm{Z} 1 * \mathrm{~m} \\
& =23 * 2 \\
& =46 \mathrm{~mm} . \\
& =\mathrm{d} 1+2 \mathrm{~m} \\
\text { Tip circle dia } & =50 \mathrm{~mm} \\
\text { Base circle dia } & =\mathrm{d} 1 \cos \alpha \\
& =46 * \cos (20) \\
& =43.22 \mathrm{~mm}
\end{aligned}
$$

Tooth thickness on Pitch circle $=\prod \mathrm{m} / 2$

$$
=3.14 \mathrm{~mm} \text {. }
$$

\subsubsection{STEER CONDITION:}

$$
(\mathrm{Wf} / \mathrm{Cxf})-(\mathrm{Wr} / \mathrm{Cxr})=\mathrm{K}
$$

(K=understeer gradient)

$\mathrm{Wf}=882.9 \mathrm{~N} \quad \mathrm{Wr}=1569.6 \mathrm{~N}$

$\mathrm{Cxf}=155.75 \mathrm{~N} / \mathrm{deg}$

$$
\mathrm{Cxr}=
$$

$267 \mathrm{~N} / \mathrm{deg}$

$$
=
$$

$(882.9 / 155.75)-(1569.6 / 267)$.

$=-0.21$ (negative) .

Since Wf $<\mathrm{Wr}$ (oversteer condition).

In this case, the lateral acceleration at the CG causes the slip angle on the rear wheel to increase than the front wheels. The outward drift at the rear of the vehicle turns the front wheel inward, thus diminishing the radius of turn.

\subsubsection{CRITICAL SPEED:}

In oversteer case, a critical speed will exist above which the vehicle will be directionally unstable.

$$
\begin{aligned}
\mathrm{V} & =\sqrt[2]{-57.3 \mathrm{Lg} / K} \\
& =65 \mathrm{~m} / \mathrm{s} .
\end{aligned}
$$

Long wheelbase vehicles will have a higher critical velocity than the shorter wheelbase vehicles.

\subsubsection{YAW VELOCITY GAIN:}

Yaw velocity $r$, is the rate of rotation in the heading angle

$$
\mathbf{r}=57.3 \mathrm{~V} / \mathrm{R}
$$

Where $\mathbf{V}$-forward speed.

$$
\text { R-radius of turn. }
$$

$$
\begin{aligned}
\mathrm{r} & =(57.3 * 65 * 5) /(18 * 1765.3) \\
& =0.586 \mathrm{deg} / \mathrm{Sec} .
\end{aligned}
$$

Yaw velocity gain is defined as the ratio of steady state yaw velocity to the steer angle.

\subsubsection{CURVATURE RESPONSE GAIN: \\ $\mathrm{CR}=(1 / \mathrm{L}) /\left(1+\mathrm{K}^{*} \mathrm{v} 2 / \mathrm{Lg}\right)$$$
=(1 / 1651) /\left(1+0.21 * 65^{\wedge} 2 / 1651 * 9.81\right)
$$$$
=0.0121 \mathrm{deg} / \mathrm{Sec}
$$

\section{UPRIGHT DESIGN AND ANALYSIS:}

\subsection{Steering Upright:}

The Steering Upright is designed in such a way that Provision is given for mounting the control arms, Tie rod, Brake calipers and space for housing the wheel assembly with the help of Stub axle. The important feature in this upright is offsetting of stub axle mounting point from its center. The main objective is to reduce the static inclination in the front side of the vehicle. This reduces the roll center height. The rear side roll center height is higher than that of the front. While cornering the vehicle, due to the elastic and geometric load transfer in the front and rear side of the vehicle tends to increase the slip angle in the rear. Hence over steer is achieved.

\subsubsection{Analysis by Ansys:}

1. Steering Upright

Step 1: Generating mesh for the upright:

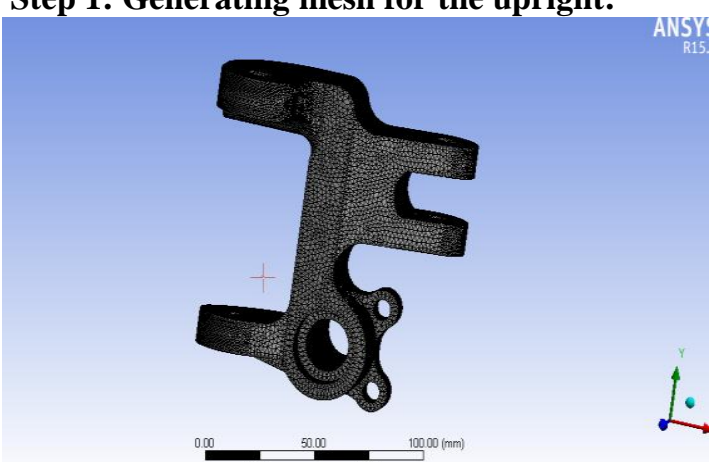

Fig 8: Meshing of upright

\section{Step 2: Fixed support is given at two points:}

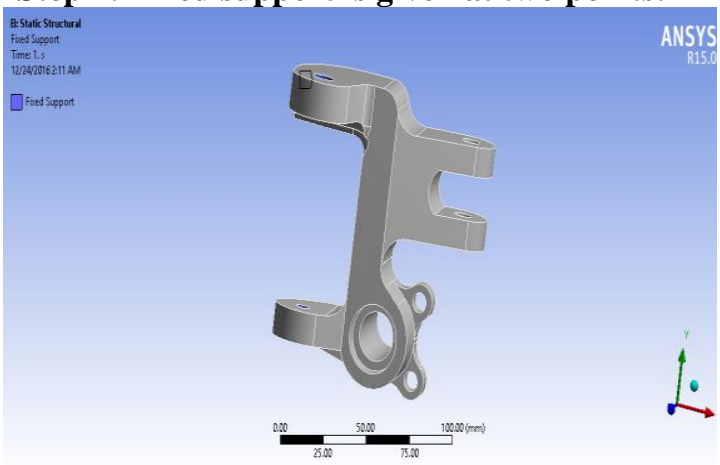

Fig 9: fixed support is given

Step 3: Bearing load of $4500 \mathrm{~N}$ is applied at the steering arm:

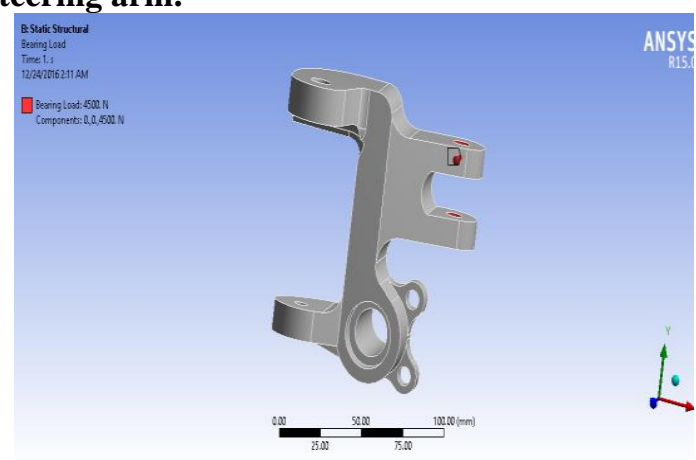

Fig 10: bearing load is applied at steering arm 

ISSN : 2248-9622, Vol. 7, Issue 5, ( Part -4) May 2017, pp.18-25

Step 4: Bearing load of $18000 \mathrm{~N}$ is applied to the spindle mount point considering one wheel landing:

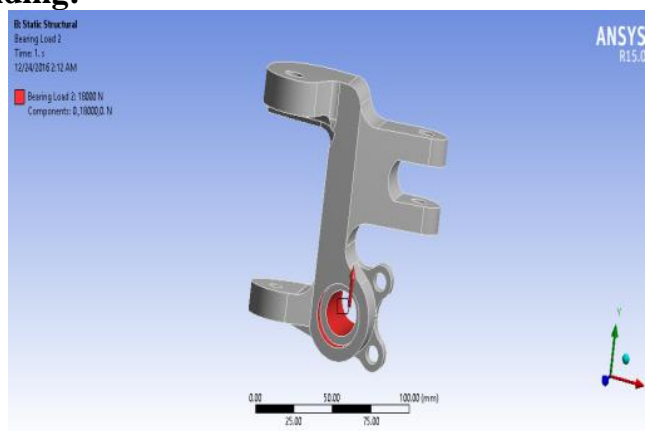

Fig 11: bearing load applied at spindle mounting point.

Step 5: A moment of $140 \mathrm{Nm}$ is applied at the caliper mounting point:

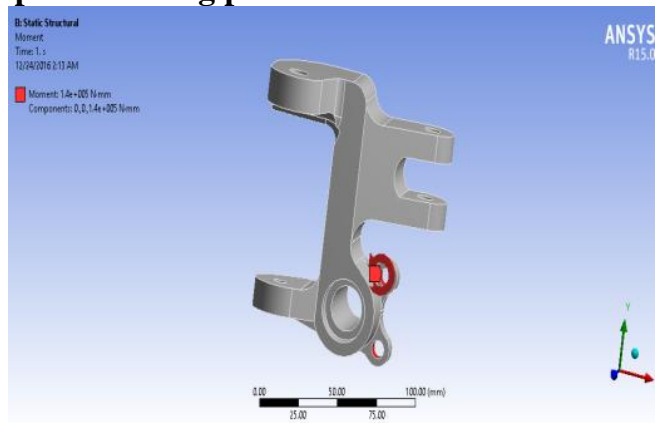

Fig 12: load applied at caliper mounting point.

Step 6: The total deformation is found out by solving the upright:

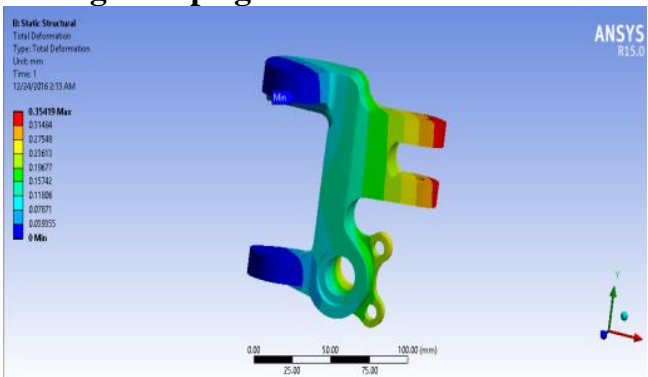

Fig 13: total deformation of knuckle

Step 7: Equivalent stress is found out:

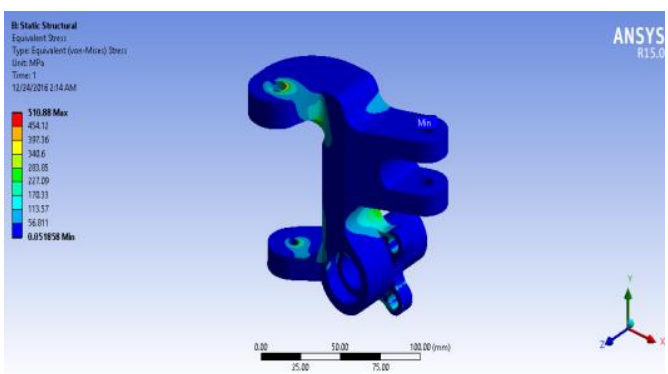

Fig 14: Equivalent stress

Step 8: Finally safety factor is checked:

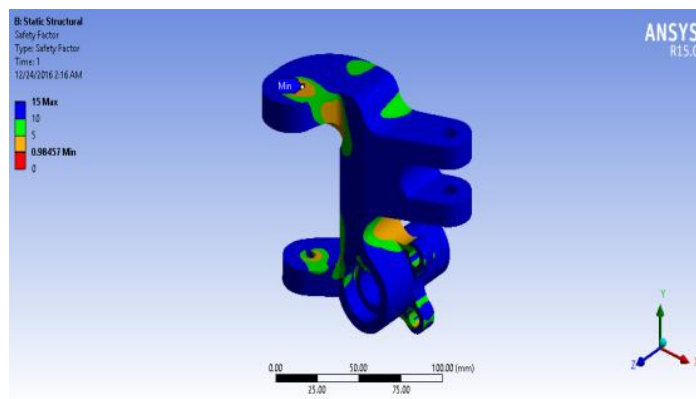

Fig 15: safety factor

2. Analysis for rack and pinion

Step 1: Remote point is applied at the surface of the pinion

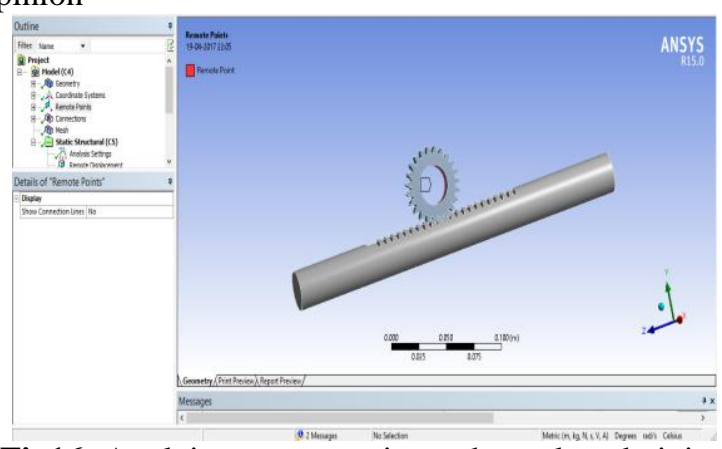

Fig16: Applying remote point at the rack and pinion

Step 2: Meshing of Rack and pinion:

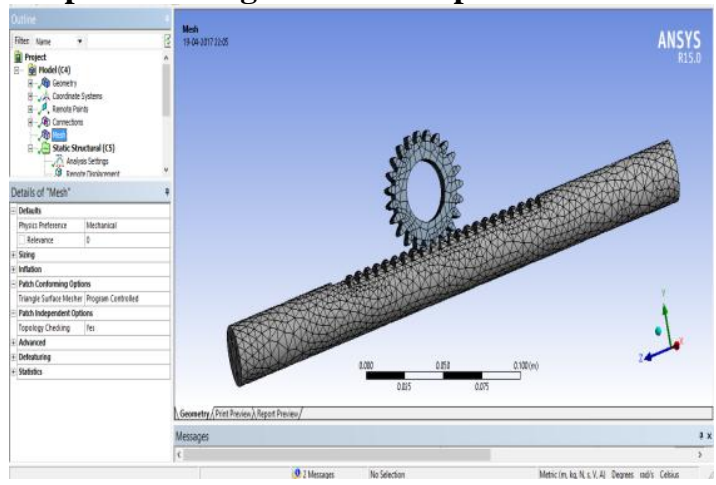

Fig17: meshing of rack and pinion

Step 3: Remote displacement is applied:

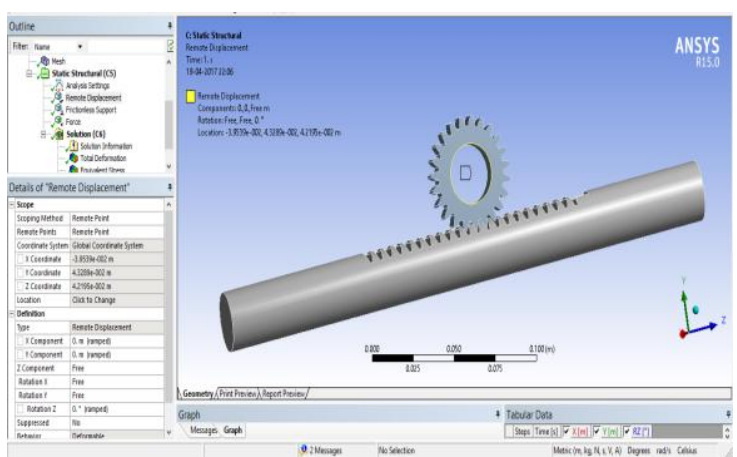

Fig18: Remote displacement is applied at the pinion surface 

ISSN : 2248-9622, Vol. 7, Issue 5, ( Part -4) May 2017, pp.18-25

Step 4: No separation is applied along the surface of the rack

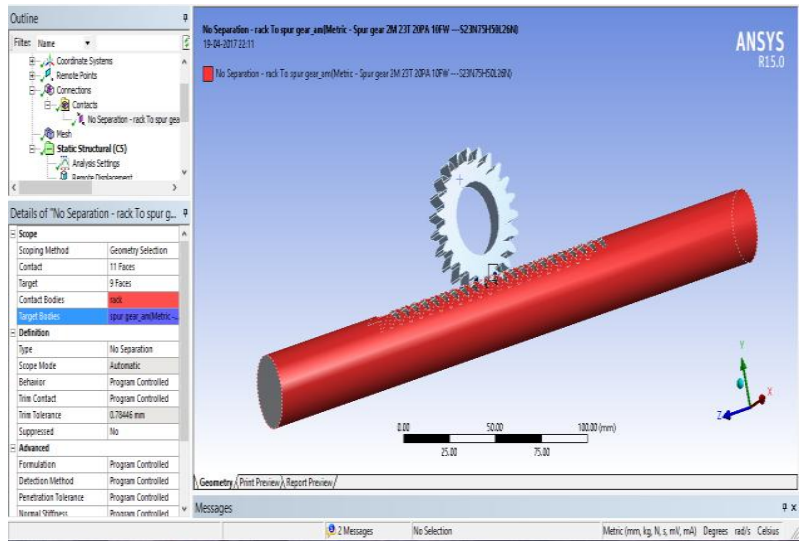

Fig19: No separation is applied along the rack surface

Step 5: Frictionless support is applied at the rack surface:

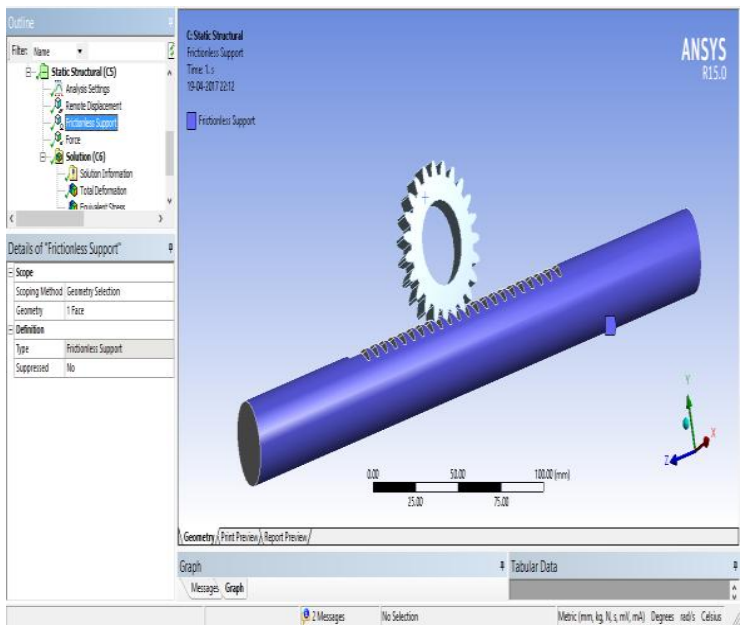

Fig20: Frictionless support is given at the rack surface

Step 6: Force is applied along the $\mathrm{z}$-axis to the rack:

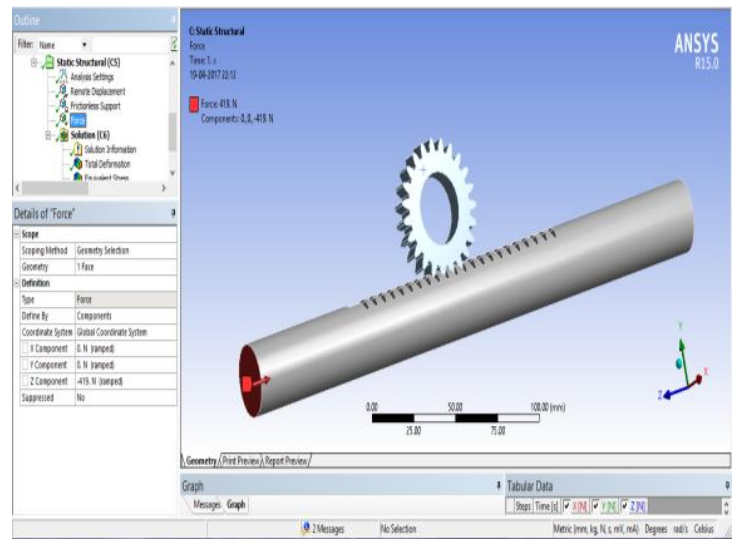

Fig21: Force applied along the $\mathrm{z}$-axis to the rack

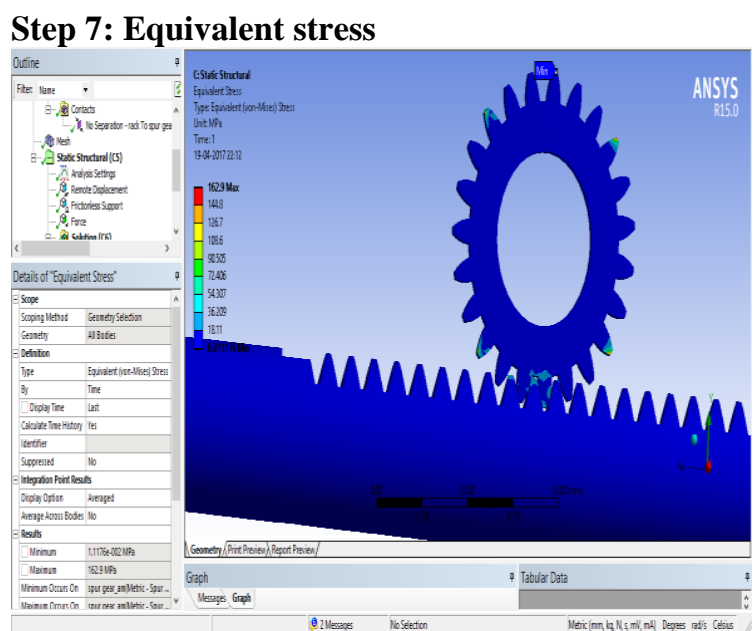

Fig22: Equivalent stress of rack and pinion

\section{Step 8: Factor of safety}

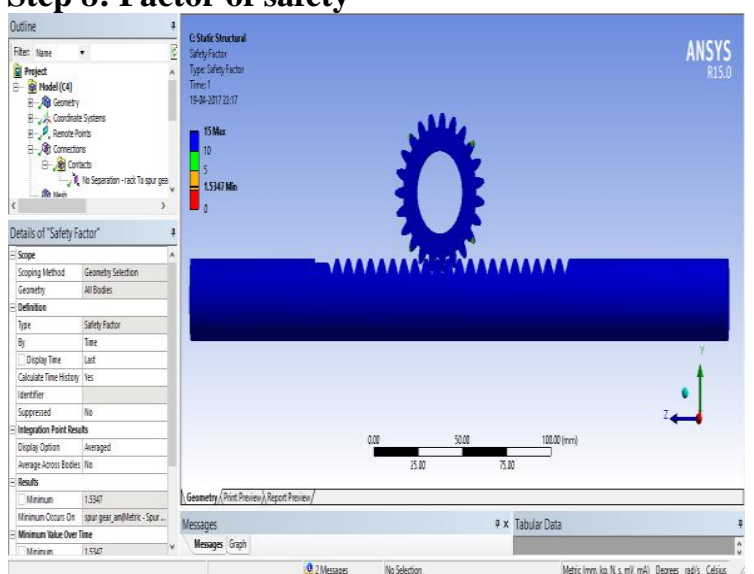

Fig23: Factor of safety

\section{LOTUS SHARK ANALYSIS:}

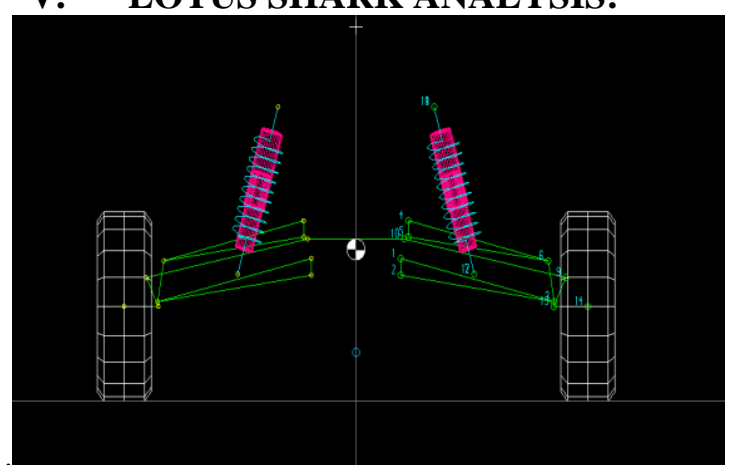

Fig 16: Steering geometry

Fig 7 shows the geometry of steering with double wishbone with lower damper and simulated for $300 \mathrm{~mm}$ arms travel for better camber, toe and caster angle variations 
5.1.1 Lotus Shark Points-Front:

Double wishbone Damper to Lower Wishbone Static values.

\begin{tabular}{|l|l|l|l|}
\hline Points. & $\mathbf{X}(\mathbf{m m})$ & $\mathbf{Y}(\mathbf{m m})$ & $\mathbf{Z}(\mathbf{m m})$ \\
\hline $\begin{array}{l}\text { Lower wishbone } \\
\text { front pivot }\end{array}$ & -1003.4 & -124.4 & -549.4 \\
\hline $\begin{array}{l}\text { Lower wishbone } \\
\text { rear pivot }\end{array}$ & -759.6 & -124.8 & -588.9 \\
\hline $\begin{array}{l}\text { Lower wishbone } \\
\text { outerball joint }\end{array}$ & -844.2 & -552.8 & -651.7 \\
\hline $\begin{array}{l}\text { Upper wishbone } \\
\text { front pivot }\end{array}$ & -985.9 & -145.8 & -459.7 \\
\hline $\begin{array}{l}\text { Upper wishbone } \\
\text { rear pivot }\end{array}$ & -748 & -145.85 & -498.2 \\
\hline $\begin{array}{l}\text { Upperwishbone } \\
\text { outerball joint }\end{array}$ & -828.5 & -533.8 & -554.8 \\
\hline $\begin{array}{l}\text { Damper wishbone } \\
\text { end }\end{array}$ & -837.8 & -329.7 & -586.5 \\
\hline Damper body end & -916.7 & -584.5 & -594.5 \\
\hline $\begin{array}{l}\text { Outer track rod } \\
\text { ball joint }\end{array}$ & -954.3 & -134.4 & -503.2 \\
\hline $\begin{array}{l}\text { Inner track rod } \\
\text { ball joint }\end{array}$ & -773.8 & -217.8 & -190.1 \\
\hline $\begin{array}{l}\text { Upper spring } \\
\text { pivot point }\end{array}$ & -837.9 & -329.7 & -586.5 \\
\hline $\begin{array}{l}\text { Lower spring } \\
\text { pivot point }\end{array}$ & -889.5 & -551.1 & -662.9 \\
\hline $\begin{array}{l}\text { Wheel spindle } \\
\text { point }\end{array}$ & -889.5 & -646.5 & -662.9 \\
\hline
\end{tabular}

Table 3: Lotus shark point.

\subsubsection{Graphs after simulation:}

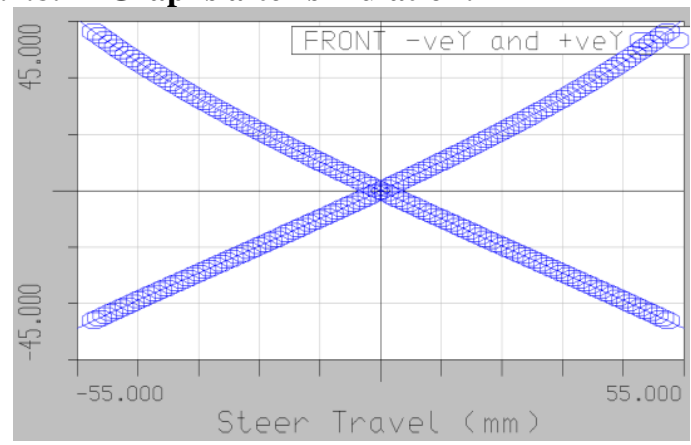

Fig 17: Steer travel Vs Toe angle

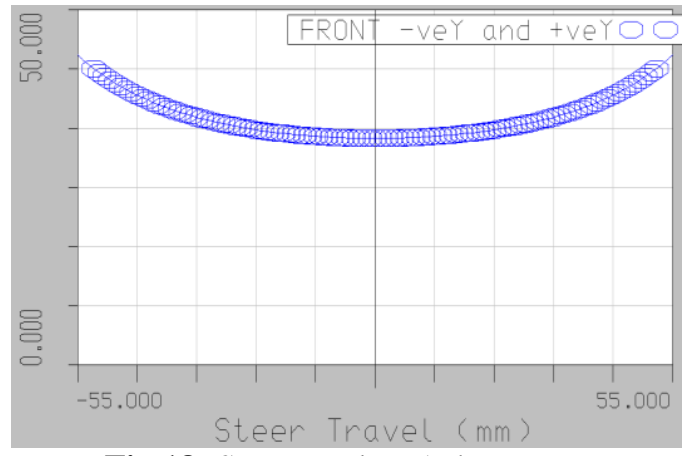

Fig 18: Steertravel vs Ackerman\%

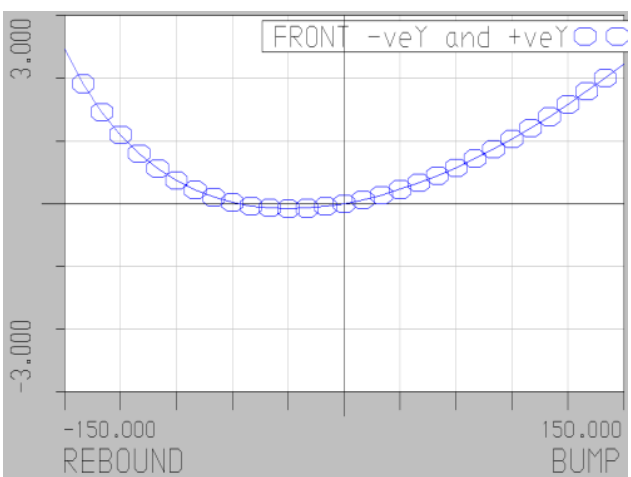

Fig 19: Bump steer vs toe angle

1.

The first graph represents the steer travel vs toe angle. The inner wheel turns at an angle of $45 \mathrm{deg}$ and outer wheel turns at angle of $35 \mathrm{deg}$ during fulllock.The high steering angle of $45 \mathrm{deg}$ is used to aid in the sharp turns.It is also made sure that the tie rod does not hit the upright,suspension arms and the wheel rim during these manuers.It is also ensured that brake hose does not bend beyond certain limit thus brake hose having only very minimal damage.

2. $45 \%$ Ackermann is obtained during full lock of steering wheel.A configuration in between parallel steering configuration and pure Ackermann configuration is used as there is considerable difeerence in the slip angle of the inner and the outer wheels. The percentage of Ackermann and the amount of bump steer were also determined for different rack travels.

Bump steer will be low when the suspesion arms and the tie rod are parallel.In our case tie is not exactly parallel to the suspension arms. The outer tie rod end is made to move in arc with inner tie rod end as its Locus.Analysis were made using Lotus software for minimal change in toe when the vehicle hits the bump.The graph shows that the angle is $3 \mathrm{deg}$ for $150 \mathrm{~mm}$ of bump travel.

\section{CONCLUSION}

The main motivation behind this project is to rectify the faults experienced and to enhance the steering characteristics of a BAJA buggy used for engineering competitions.

In order to enhance the steering characteristics, a Steering gear box and steering upright is designed. The designed parts are analysed and finally simulation is carried out.

The values obtained after the design process i.e, such as analysis and simulation is desierd to run the BAJA buggy efficiently.

\section{REFERENCES}

[1]. Design Improvement of Steering Knuckle using Shape Optimization, International Journal of Advanced Science, Vol.2, No.2, pp, 65-69, Feb 2012 
[2]. Fatigue Life Comparisons of competing Manufacturing Processes: Study of Steering Knuckle, 2003 SAE International

[3]. Zienkiewicz, Taylor, Fox, Elsevier 2014, "The Finite Element Method for Solid and Structural Mechanics".

[4]. Millikan H William SAE International 1995, "Race Car Vehicle Dynamics"

[5]. Gillespie D Thomas SAE International 1992, "Fundamentals of Vehicle Dynamics"

[6]. Jagirdar V S, Dadar M S, Sulakhe V P, Defence Science Journal March 2010 "Wishbone Structure for Front Independent Suspension of a Military Truck"

[7]. Unknown, Four wheel steering report, http://www.scribd.com/doc/34677964/Four Wheel-Steering-report, Retrived on 13th Sep 2012.

[8]. Sano s et al, "Operational and design features of the steer angle dependent four wheel steering system." 11th International conference on Experimental safety vehicles, Washington D C 1988, 5P.

[9]. Jack Erjavec., Automotive Technology, A System Approach, 5th Edition, 2010.

[10]. Lee, A.Y., "Vehicle Stability Augmentation Systems Designs for Four Wheel Steering Vehicles," ASME Journal of Dynamical Systems, Measurements and Control, Vol. 112, No. 3, pps. 489-495, September 1990.

[11]. Md. Danish Akhtar, "Wheel Steering System", International Journal of Engineering Research and Technology. ISSN Volume 6, Number 2013, 393-398.

[12]. Reza.N.Jazar, Vehicle Dynamics, Theory and applications.

[13]. B. L. Salvi, J. K. Maherchandani, Dr. B. P. Nandwana, "Developing a System for Reducing the Turning Radius of a Car", International Journal of Engineering and Innovative Technology (IJEIT) Volume 1, Issue 3, March 2012, 188-191

[14]. V. B. Bhandari "Design of Machine Elements" McGraw Hill Education India Pvt. Ltd., vol. 3, 11th Edition, 2013.

[15]. Dr.Kirpal Singh "Automobile Engineering" Standard Publishers Distributors, vol. 1, 12th Edition, 2011. 